\title{
Vocational Rehabilitation From the Client's Perspective Using the International Classification of Functioning, Disability and Health (ICF) as a Reference
}

\author{
Andrea Glässel • Monika E. Finger • \\ Alarcos Cieza - Christine Treitler • Michaela Coenen • \\ Reuben Escorpizo
}

Published online: 22 January 2011

(C) Springer Science+Business Media, LLC 2011

\begin{abstract}
Introduction A mixed-methods (qualitativequantitative), multicenter study was conducted using a focus group design to explore the lived experiences of persons in vocational rehabilitation (VR) with regard to functioning and contextual factors using six open-ended questions related to the ICF components. The results were classified by using the International Classification of Functioning, Disability and Health (ICF) as a frame of reference. Methods The meaningful concepts within the transcribed data were identified and linked to ICF
\end{abstract}

A. Glässel · M. E. Finger · A. Cieza · R. Escorpizo ( $($ ) Swiss Paraplegic Research (SPF), Guido A. Zäch Str. 4, 6207 Nottwil, Switzerland

e-mail: reuben.escorpizo@paranet.ch

A. Glässel · M. E. Finger - A. Cieza · M. Coenen · R. Escorpizo ICF Research Branch of WHO Collaborating Centre for the Family of International Classifications in German, Nottwil, Switzerland

A. Cieza $\cdot$ M. Coenen

ICF Research Branch of WHO Collaborating Centre for the Family of International Classifications in German,

Munich, Germany

M. E. Finger

Rehaklinik Bellikon, Bellikon, Switzerland

A. Cieza $\cdot$ M. Coenen

Institute for Health and Rehabilitation Sciences, Research Unit for Biopsychosocial Health, Ludwig-Maximilians Universität, Munich, Germany

C. Treitler

Berufsförderungswerk München, Kirchseeon, Germany

R. Escorpizo

Department of Health Sciences and Health Policy, University of Lucerne and SPF, Nottwil, Switzerland categories according to established linking rules. Results The seven focus groups with 26 participants yielded a total of 4,813 relevant concepts which were linked to a total of 160 different second-level ICF categories. From the client perspective, the ICF components (a) body functions, (b) activities and participation and (c) environmental factors were equally represented, while (d) body structures appeared less frequently. Out of the total number of concepts, 864 concepts (18\%) were assigned to the ICF component personal factors which is not yet classified but could indicate important aspects of resource management and strategy development of patients in VR. Conclusion Therefore, VR of patients must not be limited to anatomical and pathophysiologic changes, but should also consider a more comprehensive view which includes client's demands, strategies and resources in daily life and the context around the individual and social circumstances of their work situation.

Keywords ICF · Vocational rehabilitation . Qualitative study $\cdot$ Client perspective $\cdot$ Focus groups

\section{Introduction}

Different kinds of accidents, injuries and health conditions and their subsequent consequences may lead to disability and prevent jobholders from returning back to gainful employment. Losing paid employment can implicate further restrictions in social integration and participation [1]. Vocational rehabilitation (VR) plays an important role in reengaging disabled or injured jobholders in their professional life.

Various studies have suggested multiple aspects which were associated with successful VR or return-to-work 
programs. Selander et al. [2] reviewed risk factors around return-to-work and found that younger age, high education, marriage, social support, high self-confidence, good perceived quality of life and health, high level of control, less pain, less disability and medical complication, undergoing a multidisciplinary approach to rehabilitation, and participating in patient education have had positive VR outcomes [2]. Therefore, a comprehensive understanding of relevant aspects influencing patients functioning in VR is important [3-5].

For the World Health Organization (WHO), functioning and the ability to participate in everyday life can be understood not only as a mere consequence of disease and its treatment, but also within the context of the person that may differ greatly depending on that person's private and societal background [6]. This would imply that the biological, psychological, social and environmental aspects of everyday life must be taken into account in order to achieve a comprehensive perspective of health [7-10]. With the approval of the International Classification of Functioning, Disability and Health (ICF) [11] by the World Health Assembly in 2001 there is now a universally accepted framework to classify and describe functioning from both the patient perspective and the perspective of health professionals. The ICF is based on the integrative model of functioning and comprises four components: body functions and structures, activities and participation, and environmental and personal factors. Within these components the units of the classification, the so called ICF categories, are arranged hierarchically. These categories are

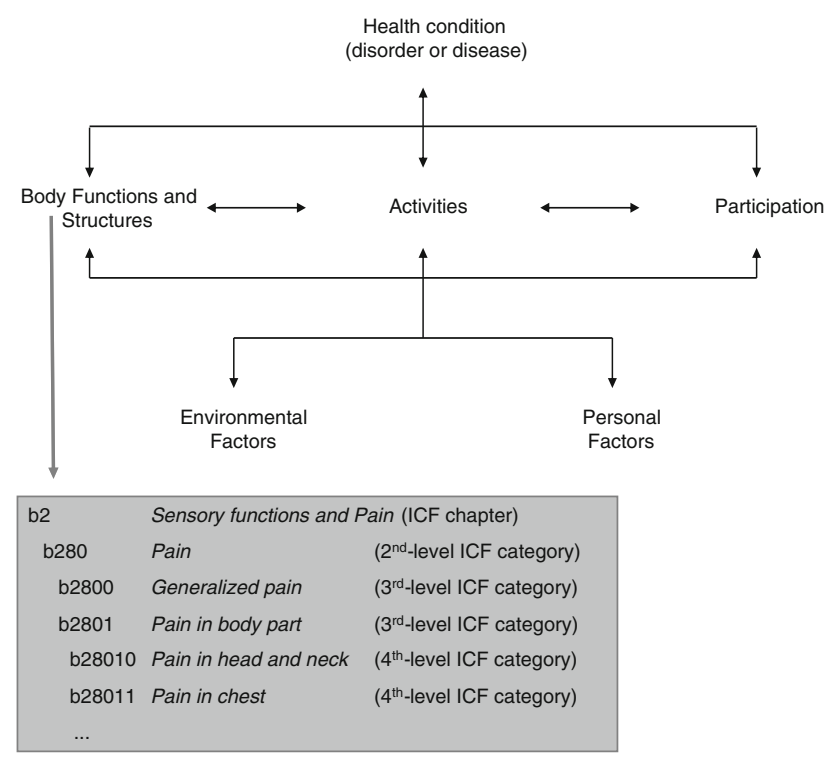

Fig. 1 The current framework of functioning and disability-the WHO International Classification of Functioning Disability and Health (ICF) divided into chapters, which constitute the first level of precision. Categories on higher levels (e.g. second- or third-level) are more detailed (Fig. 1).

Several studies show differences between the assessment of quality of life and functioning from the patient perspective compared to that from the perspective of health professionals [5, 12, 13]. When measuring and assessing daily functioning, it is important to include the patient perspective. Studies aimed at the exploration of this 'patient perspective'-in this case called 'client perspective'-frequently apply to qualitative methods, which are increasingly accepted in health research and health-related sciences [14-17].

In VR qualitative methods have been applied in different fields and health professions like general practitioners, [18, 19], conditions [20-23], the multidisciplinary team and occupational therapists [24-26] and further stakeholders [13, 27-29]. Qualitative methods provide the possibility to explore the perspective of those experience living and work situation and the disease [30]. Compared to quantitative methodology, the qualitative approach promises a greater openness to unexplored concepts or phenomena [31] and focuses on how people understand and interpret their social world [32-34]. Considering the complexity and high burden associated with VR or return-to work strategies, qualitative research in the field of VR is generally scarce in comparison to quantitative research. However, qualitative investigations around the variety of problems in functioning in persons in VR are achieving more and more interest in the literature $[23,35]$.

The objective of this study, using focus group methodology, was to identify the aspects of functioning and disability and relevant contextual environmental and personal factors from the clients' perspective in VR using the ICF as a framework in order to express them in a standardized language.

\section{Materials and Methods}

\section{Study Design}

A mixed-methods (qualitative-quantitative) study using focus group discussions was conducted. The specific methodology for identifying aspects of functioning and disability using the ICF as a framework was developed in the validation of the ICF Core Sets for rheumatoid arthritis from the client perspective [36]. Our study was part of the international co-operation project 'Development of ICF Core Sets for vocational rehabilitation' [1]. The study was approved by the responsible Ethics Committees for each of the three study centers and was performed in accordance to the Declaration of Helsinki. 
Sample

Inclusion criteria to participate in the study were (1) primary diagnosis according to the International Classification of Diseases and Health related Disorders ICD-10 that causes functional problems and that would require VR, (2) at least 18 years old, (3) competent in the German language, (4) mentally competent and capable of making decisions as attested by the investigator or health professional, (5) had been informed of and understood the purpose and rationale of the study, and (6) signed the patient consent form. Individuals who had not worked or had not been trained in gainful employment prior to participating in a VR program or retired individuals were excluded. Also individuals with significant cognitive impairment or whose main diagnosis is an acute psychiatric or psychological disorder were excluded from the study.

Clients from three centers for VR were recruited by a maximum variation sample. In order to obtain a comprehensive picture of the wide continuum of VR (i.e. maximum variation) [31] individuals of different phases (orientation and education phase) in VR and of different health conditions, disorders or injuries were included. Maximum variation in the sample means that we aim to explore the different health conditions, disorders or injuries rather than making a comparative and separate account of different diagnostic groups. The clients were conveniently recruited by health professionals like physiotherapists and registered nurses working at each study center. The health professionals were introduced to the study by the moderator (AG). The health professionals verbally explained the study to the clients and also gave them additional written information about the study. At the start of each focus group session, the moderator asked each client again whether he or she still wants to participate in the focus group interview.

Based on the experience from previous studies [36-39], the focus group size was set at a maximum of six persons to represent different opinions and facilitate interactions. The overall sample size which was defined as the number of focus groups performed-was determined by "saturation" [37, 40, 41]. Saturation is a particular concept from grounded theory [40, 41].

\section{Saturation of Data}

For the purpose of this study, saturation of data was defined as the point during data collection and analysis at which the linking of the concepts of two consecutive focus groups each revealed no more than ten percent new second-level ICF categories compared to the number of second-level ICF categories which were identified in the respective previous focus groups [37].
Data Collection and Analysis

The focus groups were conducted in two study centers in Switzerland, and in one study center in Germany. Each focus group was performed by the same moderator and a group assistant. The moderator of the focus groups (AG) has expertise in the ICF and in conducting group processes and client interviews. An established topic guide describing how to prepare and perform the focus group sessions using pre-defined open-ended questions was applied. Each question represented one ICF component. First question was on body functions, second question on body structure, third question on activities and participation, fourth question on environmental factors as barriers and as facilitators, and the last question was on personal factors. These pre-defined questions were standardized in previous ICF Core Set development studies [42, 43]. The six openended questions used are shown in Table 1.

At the beginning of the focus group session, the clients were introduced to the project and the procedure of the sessions. The open-ended questions and the titles of the ICF components were presented visually to the participants by a Power-Point presentation (Table 1). At the end of each focus group a summary of the main results was given back to enable the participants to verify and amend issues, if any. An assistant observed the process within the group [44]. Additionally, she filled in descriptive field notes according to a standardized coding schema. After each focus group, a debriefing with moderator and assistant took place to review the session [45]. All focus groups discussions were audio recorded and transcribed verbatim.

The data analysis conducted in this study followed a two-step procedure including a qualitative analysis in a narrower sense and a linking procedure to the ICF.

Table 1 Questions given to the focus group participants

1. If you think about your body and mind, what does not work the way it is supposed to? [body functions]

2. If you think about your body, in which parts are your problems? [body structures]

3. If you think about your daily life, what are your problems? [activities and participation]

4. If you think about your environment and your living conditions, what barriers do you experience? [environmental factorsbarriers]

5. If you think about your environment and your living conditions, what do you find helpful or supportive? [environmental factorsfacilitators]

6. If you think about yourself, what is important about you and the way you handle your situation of vocational rehabilitation? [personal factors]

The ICF component indicated within the brackets was not seen by the participants 


\section{Qualitative Analysis}

The meaning condensation procedure [30] was used for qualitative analysis of the data. This included an initial read through to get an overview of the content of the transcript.

Secondly, the data were divided into 'meaning units' and the theme that dominated a meaning unit was determined. A meaning unit was defined as a specific unit of text with either a few words or a few sentences with a common theme [46]. A meaning unit division did not follow linguistic grammatical rules. The text was divided where the researcher discerned a shift in meaning [30]. Finally, the concepts contained in the meaning units were identified. Meaning units could contain more than one concept.

\section{Linking to the ICF}

To be able to report the identified concepts in a systematic way and to obtain an overview of the aspects of functioning and health experienced by clients in VR from a comprehensive perspective these aspects were expressed in terms of ICF categories. Each ICF category is denoted by a code composed of a letter that refers to the respective component of the classification (b: body functions; s: body structures; $\mathrm{d}$ : activities and participation and e: environmental factors) and is followed by a numeric code starting with the chapter number (one digit), followed by the second level (two digits) and the third and fourth levels (one digit each) (Fig. 1).

The identified concepts were linked to the categories of the ICF based on established linking rules [47, 48] which allow concepts to be linked to the most precise and specific ICF categories in a systematic and standardized way (Table 2). One concept could be linked to one or more ICF categories, depending on the number of themes contained in the concept. If a concept is too general to allow a decision on the linking to a specific ICF component, chapter, or category, the statement is considered as 'not defined' (nd) (e.g. "problems with activities"). If a concept describes an aspect which is not covered by the ICF, the code 'not covered' (nc) is attributed (e.g. "The illness isn't visible for others"). Concepts identified as personal factors
Table 2 Linking process: an example

\begin{tabular}{|c|c|c|}
\hline$\longrightarrow$ & Concept $\longrightarrow$ & $\begin{array}{l}\text { ICF category } \\
\text { Linking }\end{array}$ \\
\hline $\begin{array}{l}\text { Moderator: Let's go on to the next } \\
\text { question. Next question is, } \\
\text { if you think about your } \\
\text { daily life what are your } \\
\text { problems? }\end{array}$ & & \\
\hline $\begin{array}{l}\text { Client A: Firstly, to be employed at } \\
\text { this stage is impossible, } \\
\text { because you've got so many } \\
\text { distractions and } \\
\text { malfunctions, you wouldn't } \\
\text { be able to do your job } \\
\text { properly. }\end{array}$ & $\begin{array}{l}\text { Employment is } \\
\text { impossible }\end{array}$ & $\begin{array}{l}\text { d850 Remunerative } \\
\text { employment }\end{array}$ \\
\hline $\begin{array}{l}\text { Moderator: At this stage it's } \\
\text { impossible... There are } \\
\text { further experiences or } \\
\text { problems in daily life }\end{array}$ & & \\
\hline $\begin{array}{l}\text { Client B: Yes, because you don't } \\
\text { sleep at night because I } \\
\text { have pain in my back and } \\
\text { neck. }\end{array}$ & $\begin{array}{l}\text { Problems sleeping at } \\
\text { night } \\
\text { Pain in back } \\
\text { Pain in neck }\end{array}$ & $\begin{array}{l}\text { b134 Sleep } \\
\text { functions } \\
\text { b28013 Pain in back } \\
\text { b28010 Pain in } \\
\text { head and neck }\end{array}$ \\
\hline $\begin{array}{l}\text { In the morning }(\mathrm{I}) \text { have } \\
\text { problems to dress myself }\end{array}$ & Dressing is a problem & d540 Dressing \\
\hline $\begin{aligned} \text { Client C: To concentrate on a } \\
\text { discussion with more than } \\
\text { one person, (that is) a } \\
\text { problem in (my) daily life..... }\end{aligned}$ & $\begin{array}{l}\text { Concentrate on } \\
\text { discussion }\end{array}$ & $\begin{array}{l}\text { b140 Attention } \\
\text { functions } \\
\text { d160 Focusing } \\
\text { attention }\end{array}$ \\
\hline
\end{tabular}


(e.g. "Showing others one's physical problems openly") are documented as 'pf' and the personal factors are not yet classified.

\section{Quality Assurance}

To ensure the accuracy of data analysis two strategies were conducted: First, multiple coding, which refers to the qualitative analysis and the linking to the ICF of the first focus group. In order to avoid possible bias (improve reliability), the linking was performed by two researchers with different professions, a physiotherapist (AG) and a sociologist (TB) trained in the ICF and the linking procedure. The two researchers compared their data analysis and documented their discussion. After completing the multiple coding of the first focus group a peer review was performed.

This peer review refers to analyzing and linking random samples of 15 percent of the identified concepts (of the first researcher) by the second researcher. The degree of agreement between the two researchers regarding the linked ICF categories was calculated by kappa statistic with 95 percent bootstrapped confidence intervals $(95 \% \mathrm{CI})$ $[49,50]$. The values of the kappa coefficient generally range from 0 to 1 , whereas 1 indicates perfect agreement and 0 indicates no additional agreement beyond what is expected by chance alone. The Kappa analysis was performed with SAS for Windows V9.1 (Copyright $^{(}$ 2002-2003 by SAS Institute Inc., Cary, NC, USA).

\section{Results}

Description of the Focus Groups

A total of 26 participants were included in seven focus groups. The focus group sessions lasted from about $84 \mathrm{~min}$ to $120 \mathrm{~min}$ (mean $87.5 \mathrm{~min}$ ) including a short break. The clients representing five groups of professions (handcrafter, health profession, service occupation, clerical worker, academic profession) were participating in the study. Participants' characteristics are summarized in Table 3.

Qualitative Analysis and Linking

In total, 4,813 concepts were identified in the focus groups. Out of these, 3,601 concepts $(74.8 \%)$ were linked to 160 second-level ICF categories (53 body functions' categories, 13 body structures' categories, 51 activities and participations' categories and 43 environmental factors).

However, 1,212 concepts (25.2\%) could not be linked to the ICF or specific ICF categories, respectively. Thirty-two concepts $(0.7 \%)$ were too broad to be linked to specific ICF
Table 3 Characteristics of participants and focus groups

\begin{tabular}{ll}
\hline Number of participants, $n$ & 26 \\
Median age in years (range) & $36(21-58)$ \\
Gender, $n$ female (\%) & $7(26.9 \%)$ \\
Number of focus groups, $n$ & 7 \\
Median years of work (range) & $15(2-39)$ \\
Mean duration of session (range) & 87.5 min (84-120 min) \\
Main diagnosis, $n$ & \\
Musculoskeletal traumatic disorders & 8 \\
Musculoskeletal chronic disorders & 4 \\
Internal medical disorders & 4 \\
Mental and behavioral disorders & 3 \\
Neurological traumatic disorders & 6 \\
Neurological disorders & 1 \\
\hline
\end{tabular}

categories e.g., 'physical health or general quality of life,' and were classified as not defined. Two hundred sixty-five concepts $(5.5 \%)$ had to be classified as "not covered" by the ICF. Even though these concepts refer to aspects of functioning, they could not be linked clearly to one specific ICF category with the current version of the ICF like 'overloading, overstressing, compensation, healthy risk, suicidal ideations, evaluation of the rehabilitation-program, vocational perspectives'. Eight hundred sixty-four concepts $(17.9 \%)$ were identified as personal factors-for example, autonomy, expectations to oneself, age, gender education, personal risk factors or individual coping strategies.

The 160 second-level categories identified from the client perspective represent all chapters of the ICF components body functions, activities and participation, as well as environmental factors (Tables 4, 5, 6 and 7).

Table 4 shows 53 second-level categories $(33.1 \%)$ of the component body functions. The top five categories most frequently identified in the focus groups are b126 temperament and personality functions, b130 energy and drive functions, b152 emotional functions (each in 7 out of 7 focus groups) as well as b140 attention functions and b280 pain (in 6 out of 7 focus groups). Below are actual quotes illustrating some of these categories by one participant of the focus groups (identified concepts in italics and linking examples in brackets). The excerpts below were originally in German and have been translated to English by AG and verified for their intended meaning by RE, only for illustration purpose in this paper:

...the tiredness [b1300 energy level], and sometimes the capacity to concentrate [b140 attention functions]. Especially when I have pain "attacks" [b280 sensations of pain], I am definitely more irritable [b1263 psychic stability]... 
Table 4 Fifty-three second-level ICF categories of the component body functions (b): number of focus groups in which second-level ICF categories were identified from the client perspective

\begin{tabular}{|c|c|c|}
\hline \multicolumn{2}{|c|}{ Body functions (b) } & $N^{\mathrm{a}}$ \\
\hline \multicolumn{3}{|c|}{ Chapter 1: Mental functions } \\
\hline b110 & Consciousness functions & 5 \\
\hline b122 & Global psychosocial function & 1 \\
\hline b126 & Temperament and personality function & 7 \\
\hline b130 & Energy and drive functions & 7 \\
\hline b134 & Sleep functions & 4 \\
\hline b140 & Attention functions & 6 \\
\hline b144 & Memory functions & 2 \\
\hline b147 & Psychomotor functions & 1 \\
\hline b152 & Emotional functions & 7 \\
\hline b156 & Perceptual functions & 1 \\
\hline b160 & Thought functions & 4 \\
\hline b164 & Higher-level cognitive functions & 4 \\
\hline b167 & Mental functions of language & 2 \\
\hline b180 & Experience of self and time functions & 6 \\
\hline \multicolumn{3}{|c|}{ Chapter 2: Sensory functions and pain } \\
\hline b210 & Seeing functions & 2 \\
\hline b230 & Hearing functions & 1 \\
\hline b235 & Vestibular functions & 2 \\
\hline b240 & $\begin{array}{l}\text { Sensations associated with hearing } \\
\text { and vestibular functions }\end{array}$ & 4 \\
\hline b250 & Taste functions & 1 \\
\hline b255 & Smell functions & 1 \\
\hline b265 & Touch functions & 4 \\
\hline b270 & $\begin{array}{l}\text { Sensory functions related to temperature } \\
\text { and other stimuli }\end{array}$ & 5 \\
\hline b280 & Sensations of pain & 6 \\
\hline \multicolumn{3}{|c|}{ Chapter 3: Voice and speech functions } \\
\hline b310 & Voice functions & 1 \\
\hline b330 & Fluency and rhythm of speech & 1 \\
\hline \multicolumn{3}{|c|}{$\begin{array}{l}\text { Chapter 4: Functions of the cardiovascular, } \\
\text { haematological, immunological and } \\
\text { respiratory systems }\end{array}$} \\
\hline b410 & Heart functions & 1 \\
\hline b415 & Blood vessel functions & 1 \\
\hline b420 & Blood pressure functions & 2 \\
\hline b430 & Hematological system functions & 2 \\
\hline b435 & Immunological system function & 3 \\
\hline b440 & Respiration functions & 1 \\
\hline b445 & Respiratory muscle functions & 1 \\
\hline b455 & Exercise tolerance functions & 4 \\
\hline b460 & $\begin{array}{l}\text { Sensations associated with cardiovascular } \\
\text { and respiratory functions }\end{array}$ & 1 \\
\hline \multicolumn{3}{|c|}{$\begin{array}{l}\text { Chapter 5: Functions of the digestive, metabolic } \\
\text { and endocrine systems }\end{array}$} \\
\hline b520 & Assimilation functions & 1 \\
\hline b525 & Defecations functions & 1 \\
\hline b530 & Weight maintenance functions & 5 \\
\hline
\end{tabular}

Table 4 continued

\begin{tabular}{lll}
\hline Body functions (b) & $N^{\mathrm{a}}$ \\
\hline b540 & General metabolic functions & 1 \\
b550 & Thermoregulatory functions & 1 \\
b555 & Endocrine gland functions & 1 \\
Chapter & 6: Genitourinary and reproductive functions & \\
b640 & Sexual functions & 1 \\
Chapter & 7: Neuromusculoskeletal and movement-related functions \\
b710 & Mobility of joint functions & 4 \\
b715 & Stability of joint functions & 4 \\
b720 & Mobility of bone functions & 2 \\
b730 & Muscle power functions & 5 \\
b735 & Muscle tone functions & 2 \\
b755 & Involuntary movement reaction functions & 3 \\
b760 & Control of voluntary movement functions & 2 \\
b770 & Gait pattern functions & 3 \\
b780 & Sensations related to muscles and movement & 3 \\
& functions & \\
Chapter & 8: Functions of the skin and related structures & \\
b820 & Repair functions of the skin & 1 \\
b830 & Other functions of the skin & 1 \\
b840 & Sensations related to skin & 2 \\
\hline N & & \\
\hline
\end{tabular}
${ }^{\text {a Number of focus groups }(N=7) \text { mentioning the respective ICF }}$
category

In total, thirteen second-level categories $(8.1 \%)$ belonging to body structures are listed in Table 5. Mainly structures related to movement were identified, such as s750 structure of lower extremity, s730 structure of upper extremity and, structure of trunk 5760 .

...After my injury while working [d850 remunerative employment], my right shoulder dislocated [s720 structure of shoulder] and I had rotated my knee once again [s750 structure of lower extremity].

Table 6 shows 51 second-level categories (31.9\%) identified for the component activities and participation. The top five categories identified in each of the seven focus groups are $d 240$ handling stress and other psychological demands, d570 looking after one's health, d845 acquiring, keeping and terminating a job, d850 remunerative employment, and $d 920$ recreation and leisure.

...My work [d850 remunerative employment], I still take that so seriously. You just have to (do it), $a$ mother has to function [pf-expectation]. With all the work in my household [d640 doing housework], someone needs more time and more breaks [nc-time and breaks] (but also) all the other things [nd-other things] you don't have to (do) necessarily.

Typical quotes focusing on limitations on activities and restrictions in participation are exemplified by the 
Table 5 Thirteen second-level ICF categories of the component body structures (s): Number of focus groups in which second-level ICF categories were identified from the client perspective

$\overline{\text { Body structures (s) }} N^{\mathrm{a}}$

Chapter 1: Structures of the nervous system

$\begin{array}{cl}\text { s110 Structure of brain } \\ \text { s198 } & \begin{array}{c}\text { Structure of the nervous system, } \\ \text { other specified }\end{array}\end{array}$

Chapter 2: The eye, ear and related structures

s220 Structure of eyeball

Chapter 4: Structures of the cardiovascular,

immunological and respiratory systems

$\begin{array}{ll}\text { s410 } & \text { Structure of cardiovascular system } \\ \text { s430 } & \text { structure of respiratory system }\end{array}$

Chapter 7: Structures related to movement

s710 Structure of head and neck region

s720 Structure of shoulder region

s730 Structure of upper extremity

s740 Structure of pelvic region

s750 Structure of lower extremity

s760 Structure of trunk

s770 Additional musculoskeletal structures related to movement

Chapter 8: Structures of skin

s810 Structure of areas of skin

${ }^{a}$ Number of focus groups $(N=7)$ mentioning the respective ICF category

following statement of a younger participant of one of the focus groups:

...In the past, I had an active daily life, I worked 100 percent or more [d850 Remunerative employment]. I loved my work as a handcrafter [pf- profession]. After work, I bought groceries [d620 shopping] and in the evening I meet my friends at soccer [d9201 sports]- this was my strategy to reduce my stress [d240 handling stress] but this is just not possible anymore. However, I am definitely too young to (be just) staying at home.

Table 7 shows 43 second-level categories (26.9\%) identified for the component environmental factors. The categories occurring in all seven focus groups are e110 products or substances for personal consumption, e310 immediate family, e325 acquaintances, peers colleagues, neighbours and community members, e355 health professionals, e360 health-related professionals, e570 Social security services, systems and policies, and e580 health services, systems and policies. Environmental factors may be facilitators, but they may also be perceived to be barriers as expressed in the following quote:
Table 6 Fifty-one second-level ICF categories of the component activities and participation (d): number of focus groups in which second-level ICF categories were identified from the client perspective

\begin{tabular}{lll}
\hline Activities and participation (d) & $N$ \\
\hline Chapter & 1: & Learning and applying knowledge \\
d135 & Rehearsing & 2 \\
d140 & Learning to read & 1 \\
d155 & Acquiring skills & 5 \\
d160 & Focusing attention & 5 \\
d163 & Thinking & 1 \\
d170 & Writing & 1 \\
d172 & Calculation & 1 \\
d175 & Solving problems & 3 \\
d177 & Making decisions & 2
\end{tabular}

Chapter 2: General tasks and demands

d210 Undertaking a single task 1

d220 Undertaking multiple tasks 3

d230 Carrying out daily routine 6

d240 Handling stress and other psychological demands 7

Chapter 3: Communication

d330 Speaking 3

d350 Conversation 3

d360 Using communication devices and techniques 3

Chapter 4: Mobility

d410 Changing basic body position 4

d415 Maintaining a body position 3

d430 Lifting and caring objects 4

d435 Moving objects with lower extremities 1

d440 Fine hand use 3

d445 Hand and arm use 2

d450 Walking 5

d455 Moving around 6

d460 Moving around in different locations 2

d465 Moving around using equipment 2

d470 Using transportation 2

d475 Driving 4

Chapter 5: Self-care

d520 Caring for body parts 1

d540 Dressing 2

d550 Eating 1

d570 Looking after one's health 7

Chapter 6: Domestic life

d620 Acquisition of goods and services 2

d630 Preparing meals 3

d640 Doing housework 4

d650 Caring for household objects 2

d660 Assisting others 5

Chapter 7: Interpersonal interactions and relationships

d710 Basic interpersonal interactions 2

d730 Relating with strangers 1 
Table 6 continued

\begin{tabular}{lll}
\hline Activities & and participation (d) & $N^{\mathrm{a}}$ \\
\hline d740 & Formal relationships & 4 \\
d750 & Informal social relationships & 5 \\
d760 & Family relationships & 5 \\
d770 & Intimate relationships & 4 \\
Chapter & 8: Major life areas & \\
d825 & Vocational training & 4 \\
d830 & Higher education & 1 \\
d840 & Apprenticeship (work preparation) & 7 \\
d845 & Acquiring, keeping and terminating a job & 7 \\
d850 & Remunerative employment & 7 \\
d855 & Non-remunerative employment & 2 \\
Chapter & 9: Community, social and civic life & \\
d910 & Community life & 1 \\
d920 & Recreation and leisure & 7 \\
\hline
\end{tabular}

${ }^{\text {a }}$ Number of focus groups $(N=7)$ mentioning the respective ICF category

...everything is affected by (my) kids [e310 immediate family], husband [e310 immediate family], colleagues [e325 acquaintances, peers, colleagues, neighbours and community members]...

Many participants of the focus groups focused on their experiences related to the health care system and its implication on their life:

... For me, I'm glad this didn't happen in Brazil! We do have the best health care system [e580 health services]. I feel a very good care (from) all therapists and doctors [e355 health professionals], here at the clinic. They ask me what I wanted [e450 attitudes of health professionals]; with the (help of a) social worker [e360 health-related professionals], we developed new perspectives of work [nd-perspectives of work].

...Without medication I am not able to think [pfestimation]. I need concentration [b140 attention functions] to follow the rehabilitation program. I want to take them (medication) no longer than necessary, because they don't do me any good [e1101 drugs-barrier].

However, medications were more frequently perceived to be both a facilitator and a barrier.

\section{Saturation of Data}

Saturation of the data was reached after having performed and analyzed seven focus groups (Fig. 2).
Table 7 Forty-three second-level ICF categories of the component environmental factors (e): number of focus groups in which secondlevel ICF categories were identified from the client perspective

\begin{tabular}{lr}
\hline Environmental factors (e) & $N$ \\
\hline Chapter 1: Products and Technology & \\
1,110 Products or substances for personal consumption & 7 \\
e115 Products and technology for personal use & 6 \\
$\quad$ in daily living & 3 \\
e120 Products and technology for personal indoor & \\
$\quad$ and outdoor mobility & 4 \\
e125 Products and technology for communication & 1 \\
e130 Products and technology for education & 1 \\
e135 Products and technology for employment & 1 \\
e140 Products and technology for culture, recreation & \\
$\quad$ and sports \\
e155 Design, construction and building products and & 1 \\
$\quad$ technology for use in daily living \\
e165 Assets
\end{tabular}

Chapter 2: Natural environment and human-made changes to environment

e215 Population 1

e225 Climate 5

e245 Time-related changes 1

e250 Sound 3

e260 Air quality 1

Chapter 3: Support and relationships

e310 Immediate family 7

e315 Extended family 2

e320 Friends 2

e325 Acquaintances, peers colleagues, neighbours 7 and community members

e330 People in positions of authority 4

e340 Personal care providers and personal assistants 1

e345 Strangers 3

e355 Health professionals 7

e360 Health-related professions $\quad 7$

Chapter 4: Attitudes

e410 Individual attitudes of immediate family members 5

e415 Individual attitudes of extended family members 2

e420 Individual attitudes of friends 2

e425 Individual attitudes of acquaintances, 7 peers colleagues, neighbors

e430 Individual attitudes of people in positions 6 of authority

e445 Individual attitudes of strangers 2

e450 Individual attitudes of health professionals 5

e455 Individual attitudes of health-related 5 professionals

e460 Societal attitudes

Chapter 5: Services, systems and policies

e525 Housing services, systems and policies 1

e530 Utilities services, systems and policies 2 
Table 7 continued

\begin{tabular}{lll}
\hline Environmental factors (e) & $N^{\mathrm{a}}$ \\
\hline e540 & Transportation services, systems and policies & 2 \\
e550 & Legal services, systems and policies & 3 \\
e555 & Associations and organizational services, systems and & 3 \\
& policies & 7 \\
e570 & Social security services, systems and policies & 2 \\
e575 & General social support services, systems and policies & 2 \\
e580 & Health services, systems and policies \\
e585 & Education and training services, systems and policies & 2 \\
e590 & Labor and employment services, systems and policies & 6 \\
e595 & Political services, systems and policies & 2
\end{tabular}

${ }^{\text {a }}$ Number of focus groups $(N=7)$ mentioning the respective ICF category

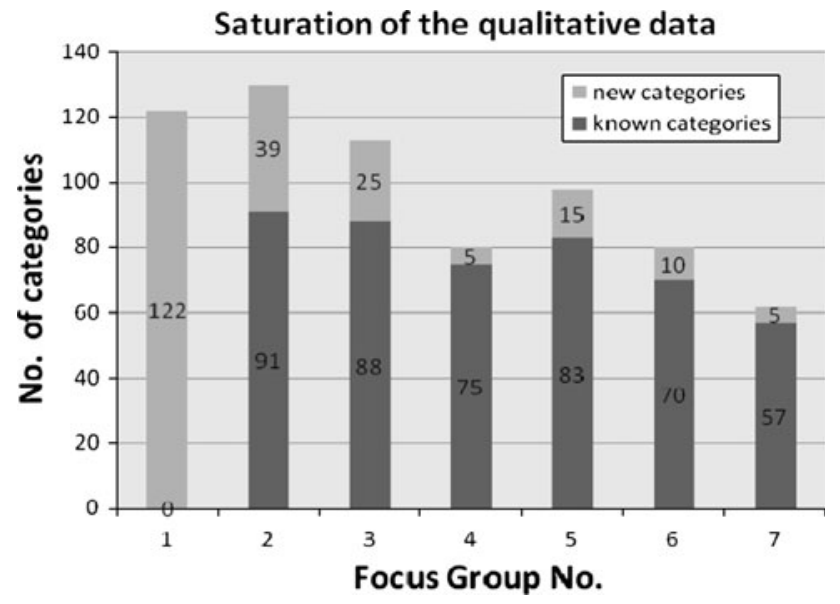

Fig. 2 Progress of saturation

Accuracy of the Analysis

The kappa coefficient for the agreement between the two researchers (peer review) was [0.65] 95\%-bootstrapped confidence interval [0.62-0.68] indicated an agreement of 70.4 percent.

\section{Discussion}

With this qualitative focus group study a wide range of aspects of functioning and disability as well as environmental and personal factors were identified from the perspective of persons in VR using the ICF as a framework. This study provided the VR community with a list of domains to describe functioning of clients in VR programs from their perspective. The motto: "Nothing about us, without us" by the United Nations [51] speaks about the importance of clients' perspective in understanding a process that affects them and this study demonstrated that.
Based on the lived experiences of persons in VR, plenty of activity limitations and participation restrictions combined with impaired body functions especially focusing on expectations and requirements in work and private life were identified from the client perspective. When asked about their problems in body parts, clients rarely mention anatomical changes as represented by the ICF component body structures. The interaction of the persons with contextual factors like, work environment, family, individual and societal attitudes and the health system may act as barriers and facilitators [5, 13, 52].

Some of the identified ICF categories need further specification.

A wide spectrum of body functions was mentioned by the participants of the focus groups covering all chapters of this component. Most of the identified body functions' categories belong to the first and seventh chapter of this component, namely mental functions and neuromusculoskeletal and movement-related functions. These categories pertain to well-known aspects which are relevant for VR of various health conditions [53, 54], such as cognitive functions (e.g. energy and drive functions, attention functions) and aspects such as mobility and stability of joint and bone, movement related functions, gait functions, movement and sensations to muscles [54]. Mobility-related categories might be associated with musculoskeletal health conditions.

The clients participating in our study reported important aspects in VR focusing on the component activities and participation which affect all life areas including health and time of recreation. Predominantly, aspects of activities and participation related to handling stress in daily life, work and private life show trade-offs between these major life areas [7].

Particularly, categories like $d 240$ handling stress and other psychological demands, d570 looking after one's health and $d 920$ recreation of leisure seem to be important aspects from the perspective of the clients in VR [26]. It is known that in clients of VR beside limitations in work performance the ability for relaxation and recreation to relieve stress is limited [55].

All four second-level ICF categories related to work and employment $d 840$ apprenticeship, $d 845$ acquiring, keeping and terminating a job, d850 remunerative employment and, d855 non-remunerative employment were identified. Altogether, there are no other comparable and comprehensive studies which accounted for the breadth of factors that we have identified in our study. Our findings found a range of domains around "work" which further support the idea of the complexity of VR.

Similarly, the interaction of the person and his or her environment remains scarcely researched [5]. The identified environmental factors having an impact on the work ability 
cover all chapters of this component which range from interventions (e.g. medication) and devices in different forms to the climate and social systems. In our study, the statements of the participants were mostly related to categories of chapter 3 support and relationships (e.g. e330 people in authority) and chapter 4 attitudes of their surrounding people (e.g. e430 individual attitudes of people in authority). Attitudes of people in authority are important for clients in VR because long-term (chronic) illness and consequences after injuries are strongly associated with returnto-work and the outcome of VR [13, 23, 56, 57]. Successful VR needs constructive collaborations to the employers and their people in authority $[3,4]$.

In VR different social systems are intertwined. Aspects related to health services and systems, the engagement with health professionals, and the social and educational system were intensively discussed in the focus groups. Positive experiences with health care providers and VR programs are reported by the participants as being important to develop new perspectives. From the client perspective established certificates and degrees are necessary to achieve successful integration to work. The participants of the focus groups extensively discussed their experiences about the perceived stress related to the complex interaction of work, family life, role expectations and financial responsibilities [54].

In addition, a vast number of experiences were identified as personal factors. Out of the total number of concepts, $18 \%$ concepts were assigned to the ICF component personal factors like, motivation, interest, autonomy, coping, beliefs, education, and ability to use mechanisms for compensation, which are not yet classified but could indicate important aspects of "personal" resource management and strategy development for patients in VR. This result stresses the importance of the individual or personal context in VR [32]. Personal factors identified in this study include important aspects related to psychosocial factors, management of resources and development of coping strategies.

In qualitative research and studies with focus group methodology, sample sizes typically remain small [44, 45, 58]. A small sample size with a diverse range of participants $(n=26)$ was used to obtain the required level of rich and meaningful data. According to Curtis et al. [59] the small samples in qualitative research are studied intensively and typically generate a large amount of information [59]. By keeping the questions open-ended, the moderator can stimulate useful trains of thought in the participants that are not anticipated [60]. The focus groups in our study were composed of three to six participants. We decided to perform groups with few participants because of the complexity of the topic and the expertise of the participants according to the literature [61]. With a small group size, each participant has a greater opportunity to talk, which is reported as an important aspect for the group dynamics in groups with elderly and ill participants [58, 62].

There are also some limitations of this study. From these findings it cannot be concluded that the encountered functional problems are equally relevant and representative for all clients in VR or equally frequent. The number of focus groups in which a specific problem came up may provide a rough impression about the potential relevance of a problem. To assess the frequency of problems in functioning further investigations using quantitative methods are needed [33].

The sample consists only of German speaking participants from Swiss, German, Brazilian, Serbian and Macedonian origin. It would be worthwhile to use the same methodology in other studies in other countries in order to establish a cross-cultural comparison of the results.

Finally, we conducted seven focus groups following the strategy of saturation of data with the criteria of two consecutive focus groups each revealing less than ten percent additional second-level ICF categories in relation to the number of second-level ICF categories identified in the respective previous focus group [37]. Participants in an eighth focus group might still report new themes and concepts not yet addressed.

It is essential to take into account that the qualitative methodology used in this study which was aimed at identifying the broadest possible range of problems. Several strategies were used to improve and verify the trustworthiness of data analysis: (1) Triangulation ensured the comprehensiveness of data. We included data triangulation by using two health professionals performing the data analysis (multiple coding) [61, 62], (2) Reflexivity was assured by filling in field notes and performing a debriefing after completing the respective focus group session, (3) Clear exposition was used establishing guidelines for conducting the focus groups (including open-ended questions), verbatim transcription, and linking rules [47, 48], and (4) Peer review as described earlier. The kappa coefficient of 0.65 for the accuracy of the peer review is comparable with other mix-method and qualitative studies using the linking rules [36, 43].

\section{Conclusions}

This study provides evidence on the importance of comprehensive conceptualizations applying qualitative and quantitative methodology and helps to holistically understand and address the impact of VR based on the biopsycho-social model of the ICF. The results confirm a comprehensive view from the client perspective. Based on these results, international standards for comprehensively describing functioning and disability of individuals in VR 
could be developed. Moreover, the findings provide us with information to help us better our planning of intervention, resource management, and strategy development. Therefore, these initial findings suggest that the VR of clients must not be limited to anatomical and pathophysiologic changes alone, but should also consider a more comprehensive view which includes client's demands, strategies and resources in daily life and the context around the individual and social circumstances of their work situation.

Acknowledgments The authors would like to express their special thanks to the health professionals who were involved in the study center organization and data collection. In Bellikon, Switzerland: Dr. Hans-Peter Gmünder, Dr. Peter Erhart, Jacqueline Huber, Markus Roth, and Beatrice Jansen. In Zurich, Switzerland: Dr. Andreas Klipstein, Edith Gitermann. In Kirchseeon, Germany: Jochen Kunert, Dr. Maria Schrör, Axel Kunz and Andrea Pfingsten. We want to thank all client/patient participants for their support and contribution to the discussion. From the ICF Research Branch and Swiss Paraplegic Research team, would like to thank Dr. Teresa Brinkel for being involved in the peer review, Katharina Strasky for her help in the transcription of the recordings of the focus groups, Anne Brust for assisting the focus groups, Miriam Lückenkemper for proof reading the manuscript, and Cristina Bostan, who is supported by a Marie Curie Fellowship from the EU funded project MURINET. This project was funded by the Swiss Accident Insurance Company (SUVA).

Conflict of Interest No conflicting interests.

\section{References}

1. Escorpizo R, Ekholm J, Gmünder HP, Cieza A, Kostanjsek N, Stucki G. Developing a core set to describe functioning in vocational rehabilitation using the international classification of functioning, disability, and health (ICF). J Occup Rehabil. 2010.

2. Selander J, Marnetoft S, Bergroth A, Ekholm J. Return to work following vocational rehabilitation for neck, back and shoulder problems: risk factors reviewed. Disabil Rehabil. 2002;24(14): 704-12.

3. Young AE. Return to work following disabling occupational injury-facilitators of employment continuation. Scand J Work Environ Health. 2010.

4. Young AE. Employment maintenance and the factors that impact it after vocational rehabilitation and return to work. Disabil Rehabil. 2010;32(20):1621-32.

5. Slebus FG, Sluiter JK, Kuijer PP, Willems JH, Frings-Dresen MH. Work-ability evaluation: a piece of cake or a hard nut to crack? Disabil Rehabil. 2007;29(16):1295-300.

6. World Health Organization. WHO Rehabilitation after cardiovascular diseases, with special emphasis on developing countries. Report of WHO expert committee. Geneva: WHO; 1993.

7. O'Donovan MA, Doyle A, Gallagher P. Barriers, activities and participation: incorporating ICF into service planning datasets. Disabil Rehabil. 2009;31(25):2073-80.

8. Sandberg MA, Bush SS, Martin T. Beyond diagnosis: understanding the healthcare challenges of injured veterans through the application of the International Classification of Functioning, Disability and Health (ICF). Clin Neuropsychol. 2009;23(8): 1416-32.
9. Homa DB. Using the International Classification of Functioning, Disability and Health (ICF) in job placement. Work. 2007;29(4): 277-86.

10. Fantoni SQ, Peugniez C, Duhamel A, Skrzypczak J, Frimat P, Leroyer A. Factors related to return to work by women with breast cancer in northern France. J Occup Rehabil. 2010;20(1): $49-58$.

11. World Health Organization. International Classification of Functioning, Disability and Health: ICF. Geneva: WHO; 2001.

12. Keus F, de Vries J, Gooszen HG, van Laarhoven CJ. Assessing factors influencing return back to work after cholecystectomy: a qualitative research. BMC Gastroenterol. 2010;10:12.

13. Tjulin A, Edvardsson Stiwne E, Ekberg K. Experience of the implementation of a multi-stakeholder return-to-work programme. J Occup Rehabil. 2009;19(4):409-18.

14. Mays N, Pope C. Qualitative research in health care: assessing quality in qualitative research. BMJ. 2000;320:50-2.

15. Pope C, Ziebland S, Mays N. Qualitative research in health care. Analysing qualitative data. BMJ. 2000;320(7227):114-6.

16. Giacomini M, Cook D. Users' guides to the medical literature: XXIII. Qualitative research in health care, A. Are the results of the study valid. JAMA. 2000;284:357-62.

17. MacEachen E, Kosny A, Ferrier S. Unexpected barriers in return to work: lessons learned from injured worker peer support groups. Work. 2007;29(2):155-64.

18. Cohen D, Marfell N, Webb K, Robling M, Aylward M. Managing long-term worklessness in primary care: a focus group study. Occup Med. 2010;60(2):121-6.

19. Pincus T, Woodcock A, Vogel S. Returning back pain patients to work: how private musculoskeletal practitioners outside the National Health Service perceive their role (an interview study). J Occup Rehabil. 2010;20(3):322-30.

20. Dunn EC, Wewiorski NJ, Rogers ES. A qualitative investigation of individual and contextual factors associated with vocational recovery among people with serious mental illness. Am J Orthopsychiatry. 2010;80(2):185-94.

21. Alaszewski A, Alaszewski H, Potter J, Penhale B. Working after a stroke: survivors' experiences and perceptions of barriers to and facilitators of the return to paid employment. Disabil Rehabil. 2007;29(24):1858-69.

22. Coutu MF, Baril R, Durand MJ, Cote D, Rouleau A, Cadieux G. Transforming the meaning of pain: an important step for the return to work. Work. 2010;35(2):209-19.

23. Johnsson A, Fornander T, Rutqvist LE, Olsson M. Factors influencing return to work: a narrative study of women treated for breast cancer. Eur J Cancer Care. 2010;19(3):317-23.

24. Buijs PC, Lambeek LC, Koppenrade V, Hooftman WE, Anema JR. Can workers with chronic back pain shift from pain elimination to function restore at work? Qualitative evaluation of an innovative work related multidisciplinary programme. J Back Musculoskelet Rehabil. 2009;22(2):65-73.

25. Stergiou-Kita M, Yantzi A, Wan J. The personal and workplace factors relevant to work readiness evaluation following acquired brain injury: occupational therapists' perceptions. Brain Inj. 2010; 24(7-8):948-58.

26. Cowls J, Galloway E. Understanding how traumatic re-enactment impacts the workplace: assisting clients' successful return to work. Work. 2009;33(4):401-11.

27. Gardner BT, Pransky G, Shaw WS, Nha Hong Q, Loisel P. Researcher perspectives on competencies of return-to-work coordinators. Disabil Rehabil. 2010;32(1):72-8.

28. Ammendolia C, Cassidy D, Steensta I, Soklaridis S, Boyle E, Eng $\mathrm{S}$, et al. Designing a workplace return-to-work program for occupational low back pain: an intervention mapping approach. BMC Musculoskelet Disord. 2009;10:65. 
29. Pransky G, Shaw WS, Loisel P, Hong QN, Desorcy B. Development and validation of competencies for return to work coordinators. J Occup Rehabil. 2010;20(1):41-8.

30. Kvale S. Interviews- an introduction to qualitative research interviewing. California: Sage; 1996.

31. Patton MQ. Qualitative evaluation and research methods. 2nd ed. Thousand Oaks: Sage; 1990.

32. Dekkers-Sanchez PM, Wind H, Sluiter JK, Frings-Dresen MH. A qualitative study of perpetuating factors for long term sick leave and promoting factors for return to work: chronic work disabled patients in their own words. J Rehabil Med. 2010;42(6):544-52.

33. Cabral LH, Sampaio RF, Figueiredo IM, Mancini MC. Factors associated with return to work following a hand injury: a qualitative/quantitative approach. Rev Bras Fisioter. 2010;14(2):149-57.

34. Joyce KE, Smith KE, Henderson G, Greig G, Bambra C. Patient perspectives of condition management programmes as a route to better health, well-being and employability. Fam Pract. 2010;27(1): 101-9.

35. Chan SK, Man DW. Barriers to returning to work for people with spinal cord injuries: a focus group study. Work. 2005;25(4): 325-32.

36. Coenen M, Cieza A, Stamm TA, Amann E, Kollerits B, Stucki G. Validation of the International Classification of Functioning, Disability and Health (ICF) core Set for rheumatoid arthritis from the patient perspective using focus groups. Arthritis Res Ther. 2006;8(4):R84.

37. Kirchberger I, Sinnott A, Charlifue S, Kovindha A, Luthi H, Campbell R, et al. Functioning and disability in spinal cord injury from the consumer perspective: an international qualitative study using focus groups and the ICF. Spinal Cord. 2010;48(8):603-13.

38. Kirchberger I, Coenen M, Hierl FX, Dieterle C, Seissler J, Stucki G, et al. Validation of the International Classification of Functioning, Disability and Health (ICF) core set for diabetes mellitus from the patient perspective using focus groups. Diabet Med. 2009; 26(7):700-7.

39. Hieblinger R, Coenen M, Stucki G, Winkelmann A, Cieza A. Validation of the International Classification of Functioning, Disability and Health core set for chronic widespread pain from the perspective of fibromyalgia patients. Arthritis Res Ther. 2009; 11(3):R67.

40. Glaser BG, Strauss A. Discovery of grounded theory. Strategies for qualitative research. Mill Valley: Sociology Press; 1967.

41. Strauss A, Corbin J. Basics of qualitative research: grounded theory. Procedures and technique. 2nd ed. NewburyPark: Sage; 1998.

42. Gradinger F, Köhler B, Khatami R, Mathis J, Cieza A, Bassetti C. Problems in functioning from the patient perspective using the International Classification of Functioning, Disability and Health (ICF) as a reference. J Sleep Res. 2010.

43. Tschiesner U, Linseisen E, Coenen M, Rogers S, Harreus U, Berghaus A, et al. Evaluating sequelae after head and neck cancer from the patient perspective with the help of the International Classification of Functioning, Disability and Health. Eur Arch Otorhinolaryngol. 2009;266(3):425-36.
44. Krueger R, Casey M. Focus groups: a practical guide for applied research. Thousand Oaks: Sage; 2000.

45. Depoy E, Gitlin LN. Introduction to research. St. Louis: Mosby; 1998.

46. Karlsson G. Psychological qualitative research from a phenomenological perspective. Stockholm: Almqvist \& Wiksell International; 1993.

47. Cieza A, Brockow T, Ewert T, Amman E, Kollerits B, Chatterji $\mathrm{S}$, et al. Linking health-status measurements to the International Classification of Functioning, Disability and Health. J Rehabil Med. 2002;34(5):205-10

48. Cieza A, Geyh S, Chatterji S, Kostanjsek N, Ustun B, Stucki G. ICF linking rules: an update based on lessons learned. J Rehabil Med. 2005;37(4):212-8.

49. Cohen J. A coefficient of agreement for nominal scales. Educ Psychol Measur. 1960;20:37-46.

50. Vierkant R. A SAS macro for calculating bootstrapped confidence intervals about a kappa coefficient. Marshfield: Medical Research Foundation. Available from: http://www2.sas.com/ proceedings/sugi22/STATS/PAPER295.PDF. 2010.

51. United Nations Convention of the rights of Persons with Disabilities. In: U.NATIONS (Ed, New York, 2006).

52. Young AE. Return-to-work experiences: prior to receiving vocational services. Disabil Rehabil. 2009;31(24):2013-22.

53. Brouwers EP, Terluin B, Tiemens BG, Verhaak PF. Predicting return to work in employees sick-listed due to minor mental disorders. J Occup Rehabil. 2009;19(4):323-32.

54. Lydell M, Grahn B, Mansson J, Baigi A, Marklund B. Predictive factors of sustained return to work for persons with musculoskeletal disorders who participated in rehabilitation. Work. 2009;33(3): 317-28.

55. Stice BD, Dik BJ. Depression among injured workers receiving vocational rehabilitation: contributions of work values, pain, and stress. J Occup Rehabil. 2009;19(4):354-63.

56. Tjulin A, Maceachen E, Ekberg K. Exploring workplace actors experiences of the social organization of return-to-work. J Occup Rehabil. 2010;20(3):311-21.

57. Amir Z, Wynn P, Chan F, Strauser D, Whitaker S, Luker K. Return to work after cancer in the UK: attitudes and experiences of line managers. J Occup Rehabil. 2009.

58. Morgan DL. Focus groups as qualitative research. 2nd ed. Newbury Park: Sage; 1997.

59. Curtis S, Gesler W, Smith G, Washburn S. Approaches to sampling and case selection in qualitative research: examples in the geography of health. Soc Sci Med. 2000;50:1001-14.

60. Knodel J. The design and analysis of focus group studies. In: Morgan DL, editor. Successful focus groups. Newbury Park: Sage; 1993. p. 35-50.

61. Krueger RA. The future of focus groups. Qual Health Res. 1995;5(4):524-30.

62. Carey A. The group effect in focus groups: planning, implementing, and interpreting focus group research. 1994; 225-41. 